Check for updates

Cite this: RSC Adv., 2018, 8, 35150

Received 17th July 2018

Accepted 5th October 2018

DOI: $10.1039 / c 8 r a 06059 b$

rsc.li/rsc-advances

\title{
Facile fabrication of zinc oxide coated superhydrophobic and superoleophilic meshes for efficient oil/water separation $\dagger$
}

\author{
Yuezhong Zhang, (D) *a Xiaoyu Wang, ${ }^{\mathrm{b}}$ Chunhui Wang, ${ }^{\mathrm{b}}$ Jiangjiang Liu, \\ Hongbiao Zhai, ${ }^{b}$ Baosheng Liu, ${ }^{* b}$ Xudong Zhao $^{a}$ and Daqing Fang ${ }^{b}$
}

\begin{abstract}
Zinc oxide $(\mathrm{ZnO})$ coated superhydrophobic and superoleophilic stainless steel meshes are facilely fabricated via chemical immersion growth and subsequent surface modification. The as-prepared meshes show good mechanical durability, chemical stability and corrosion-resistant properties due to a combination of the hierarchical $\mathrm{ZnO}$ structure and the low surface energy modification. More importantly, the as-prepared meshes are used for highly efficient separation of various oil/water mixtures. Meanwhile, a new oil skimmer based on the as-prepared mesh is proposed to spontaneously collect floating oil with high separation efficiency and desirable durability.
\end{abstract}

\section{Introduction}

Oily wastewater has become a serious world-wide environmental problem resulting from untreated industrial wastewater, sanitary wastewater and oil spillage accidents..$^{\mathbf{1 - 4}}$ Therefore, it is necessary and imperative to develop some facile, highly-efficient and inexpensive technologies to assistant in the treatment and purification of oily wastewater.

Inspired by nature, the exploration and development of novel separation membranes with special wettability is deemed to be facile and effective., ${ }^{5,6}$ In recent years, superwettable membranes (superhydrophobicity/superoleophilicity $^{7-10}$ or superhydrophilicity/underwater superoleophobicity ${ }^{\mathbf{1 1 - 1 5}}$ ) have been used to separate oil/water mixtures utilizing the opposite wettability of the oil and water phases. Therefore, exploration of various oil/water separation membranes based on special wettability has become a popular topic. Recently, porous metal materials, such as copper mesh, steel mesh and nickel foam, have been widely investigated as promising substrates for separating oil from sewage. ${ }^{\mathbf{1 6 - 1 8}}$ Among the investigated porous metal materials, stainless steel mesh has gained special attention owing to its being cost-effective, and having high strength, flexibility and direct application in industry. As is well known, both constructing micro-nano scale structures and modification by low surface energy material are essential for fabricating

${ }^{a}$ College of Chemical and Biological Engineering, Taiyuan University of Science and Technology, Taiyuan, Shanxi 030024, China. E-mail: yuezhongzhang@sina.cn ${ }^{b}$ College of Materials Science and Engineering, Taiyuan University of Science and Technology, Taiyuan, Shanxi 030024, China. E-mail: liubaosheng@tyut.edu.cn

$\dagger$ Electronic supplementary information (ESI) available. See DOI: 10.1039/c8ra06059b superhydrophobic surface on stainless steel meshes. Despite a number of methods have been proposed, facile construction of micro- and nanostructures on stainless steel mesh substrate for efficient oil/water separation is still a challenge.

Recently, ZnO, as a structural material, especially microstructures and nanostructures are popularly employed to fabricate special wettability surface due to its special physical and chemical properties. For example, Chen et al. applied femtosecond laser method to fabricate directly $\mathrm{ZnO}$ superhydrophobic surface on Zn substrate. ${ }^{19}$ Huang et al. reported a superhydrophobic $\mathrm{ZnO}$ thin film on aluminum alloy substrate via electrodeposition method. ${ }^{20}$ Velayi et al. fabricated superhydrophobic ZnO surfaces with reversible wettability. ${ }^{21}$ Furthermore, some different approaches have been also reported to prepare $\mathrm{ZnO}$ micro/nanostructures on stainless steel mesh, such as electrodeposition, ${ }^{22,23}$ solgel $^{24,25}$ and chemical vapor deposition. ${ }^{23}$ However, most of the methods have limitations in practical fabrication, especially for large-scale fabrication, owing to complicated processes, expensive raw materials, and sophisticated equipment.

In this paper, we developed a simple, inexpensive and scalable approach to fabricate superhydrophobic and superoleophilic surface on the stainless steel meshes via $\mathrm{ZnO}$ microstructures construction process and low surface energy modification process. The as-prepared mesh exhibits good mechanical durability, chemical stability and corrosionresistant properties. The as-prepared mesh can be used for separating various oil/water mixtures solely driven from gravity and spontaneous slick collection. What's more, the mesh still exhibits a separation efficiency above 95\% and this collection system can be reused and the oil collection rate can reach $>96 \%$. 


\section{Experimental}

\section{Materials}

Stainless steel meshes (400 mesh, Taitong Metal Mesh Ltd., China) with a size of $35 \mathrm{~mm} \times 35 \mathrm{~mm}$ was used as the substrate. Zinc acetate dehydrate, zinc nitrate hexahydrate, ammonia and stearic acid $\left(\mathrm{C}_{18} \mathrm{H}_{36} \mathrm{O}_{2}\right)$ were used as received (analytical grade, Sinopharm Chemical Reagent Co., Ltd., China).

\section{Sample preparation}

The superhydrophobic and superoleophilic stainless steel mesh was prepared by the following procedures: (1) pretreatment for substrate. The stainless steel mesh was cleaned ultrasonically in ethanol and distilled water respectively to remove the dirt on the surface. (2) Preparing $\mathrm{ZnO}$ microstructures. The stainless steel mesh was immersed in a $40 \mathrm{mmol} \mathrm{L}^{-1}$ aqueous zinc acetate ethanol solution for $5 \mathrm{~min}$ and dried in air, and then it was annealed at $350{ }^{\circ} \mathrm{C}$ for $30 \mathrm{~min}$ to form a $\mathrm{ZnO}$ seed layer on the steel mesh substrate. In the next step, the pretreated substrate was immersed vertically in an aqueous solution of zinc nitrate hexahydrate $\left(40 \mathrm{mmol} \mathrm{L}^{-1}\right)$ and ammonium hydroxide $\left(1.0 \mathrm{~mol} \mathrm{~L}^{-1}\right)$. The solution was heated in an oil bath at $90{ }^{\circ} \mathrm{C}$ for $9 \mathrm{~h}$. Then, the mesh was removed from the solutions, washed with deionized water and dried at in air. (3) Modification of stearic acid. The $\mathrm{ZnO}$ coated mesh was immersed in a mixed solution of ethanol $(15 \mathrm{~mL})$ and stearic acid $(0.12 \mathrm{~g})$ for $12 \mathrm{~h}$ and finally heated at $100{ }^{\circ} \mathrm{C}$ for $1 \mathrm{~h}$. The schematic illustration of the fabrication process is shown in Fig. 1.

\section{Characterization}

The morphological structures of the as-prepared mesh surfaces were examined by scanning electron microscopy (SEM, Hitachi S-4800). The BET specific surface areas of the meshes were characterized by an Auto-IQ-MP (Quantachrome Instruments) using $\mathrm{N}_{2}$ adsorption at $77 \mathrm{~K}$. The infrared spectra of the samples were investigated by using Fourier transform infrared spectrometry (FTIR, Nicolet iN10). Surface chemical composition of the samples was investigated by X-ray photoelectron spectrometer (XPS, Thermoelectron ESCALAB 250). The water and oil contact angles (CAs) were measured with a JC2000C apparatus at ambient temperature. The volume of the individual

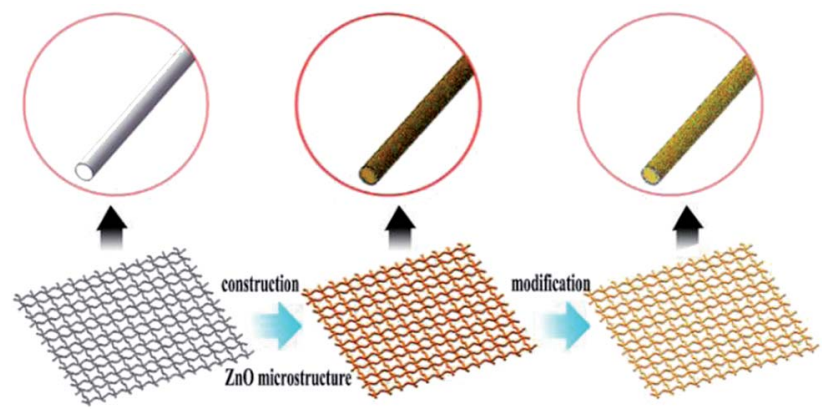

Fig. 1 Schematic illustration of the fabrication process of superhydrophobic stainless steel mesh. water droplet used in all measurements was $3 \mu \mathrm{L}$. The average CA were obtained by measuring the same sample in at least five different positions.

\section{Mechanical durability test}

The mechanical durability of the samples was examined by mechanical bending and twisting test and scratch test. The morphology of superhydrophobic meshes after mechanical bending and twisting was investigated. The as-prepared superhydrophobic mesh $(30 \mathrm{~mm} \times 30 \mathrm{~mm})$ was placed on sandpaper (\#200) with a pressure of $1.09 \mathrm{kPa}$ (100 $\mathrm{g}$ force) and as-prepared superhydrophobic mesh was selected to be moved back tangentially on the sandpaper in two orthogonal directions. The distance of each movement was $10 \mathrm{~cm}$ for each direction. The evolution of WCA was measured for different cycles.

\section{Corrosion resistances measurement}

The corrosion resistances of the samples were investigated by electrochemical measurements in $3.5 \mathrm{wt} \% \mathrm{NaCl}$ solution at $25{ }^{\circ} \mathrm{C}$. Electrochemical measurements were conducted in a three-electrode cell using a platinum counter electrode and an $\mathrm{Ag} / \mathrm{AgCl}$ reference electrode. Potentiodynamic polarization curves were measured in with the scanning rate of $0.5 \mathrm{mV} \mathrm{s}^{-1}$.

\section{Oil/water separation and floating oil collection test}

The oil/water separation measurement was performed on a homemade equipment (Fig. 7a). The oil/water mixtures (50\%, $\mathrm{v} / \mathrm{v}$ ) were poured onto the as-prepared superhydrophobic and superoleophilic mesh. The floating oil collection test was performed on a homemade oil skimmer (Fig. 8a), in which the asprepared mesh was mounted on the open end of a bottle using a cap with a hole of $13 \mathrm{~mm}$ and the steel beads are used to overcome buoyancy to increase the contact area between the mesh and the floating oil. The separation or collection efficiency was calculated according to $\eta=\left(m_{1} / m_{0}\right) \times 100 \%$, where $m_{0}$ and $m_{1}$ are the mass of the oil before and after the separation process, respectively.

\section{Recycling test}

The oil/water separation efficiency versus the recycle numbers were tested using hexane/water mixture. After oil/water separation, the contaminated mesh was cleaned with alcohol to remove the absorbed oil and rinsed with deionized water. Finally, the cleaned mesh was dried at $60{ }^{\circ} \mathrm{C}$ for $40 \mathrm{~min}$ and the superhydrophobicity could be recovered.

\section{Results and discussion}

\section{Surface morphology and chemical composition analysis}

Typical SEM images at different magnifications of the stainless steel meshes surface are shown in Fig. 2. Fig. 2a and b indicate the pristine stainless steel mesh with an average wire diameter of approximately $40 \mu \mathrm{m}$ to form the reticulated structure with pore size about $50 \mu \mathrm{m}$. The wire surface of the pristine mesh is smooth (Fig. 2c). The $\mathrm{ZnO}$-coated mesh retains its original pore 



Fig. 2 SEM images of the stainless-steel meshes surface: $(a-c)$ pristine mesh, $(\mathrm{d}-\mathrm{f}) \mathrm{ZnO}$ coated mesh and $(\mathrm{g}-\mathrm{i})$ superhydrophobic stainless steel mesh, respectively.

size and wire diameter without apparent variation (Fig. $2 \mathrm{~d}$ and e). However, regular microstructures are formed on the stainless steel wire surface. The corresponding high magnification SEM image reveals that the microstructure consists of irregular rod-like with a diameter ranging from $300 \mathrm{~nm}$ to $400 \mathrm{~nm}$ and length of 2-4 $\mu \mathrm{m}$ (Fig. 2f). After modification with the stearic acid, more micro-nano protrusions are observed on superhydrophobic stainless steel mesh (Fig. 2g). The magnified SEM images (Fig. $2 \mathrm{~h}$ and i) show the randomly distributed clustered structure consisting of nanosheets. Furthermore, the specific surface areas of the meshes were characterized and $\mathrm{N}_{2}$ adsorption isotherms at $77 \mathrm{~K}$ were shown in Fig. S1. $\dagger$ The BET surface areas of pristine mesh, $\mathrm{ZnO}$ coated mesh and superhydrophobic mesh were calculated to $0.331,0.968$ and $4.555 \mathrm{~m}^{2}$ $\mathrm{g}^{-1}$ respectively. The increase in specific surface area contributes to increased surface roughness after $\mathrm{ZnO}$ construction and modification process. This constructed micro- and nano-scale hierarchical structures are essential for endowing superhydrophobicity.

The constructed $\mathrm{ZnO}$ microstructure and the presence of low surface energy chemical functional groups after modification process are supported by the XPS and FTIR spectra. Fig. 3 shows XPS results of the superhydrophobic stainless steel mesh surface. The existence of elements $\mathrm{Zn}, \mathrm{O}$, and $\mathrm{C}$ is confirmed from the survey XPS spectra (Fig. 3a). The Zn 2p3/2 and 2p1/2 peaks (Fig. $3 \mathrm{~b}$ ) are centered at 1022.1 and $1045.3 \mathrm{eV}$, respectively, which are assigned to $\mathrm{Zn}^{2+} .{ }^{26}$ The high-resolution $\mathrm{C} 1 \mathrm{~s}$ spectrum (Fig. 3c) can be fitted by three peaks respectively centered at $288.7 \mathrm{eV}, 285.2 \mathrm{eV}$ and $284.7 \mathrm{eV}$, which can be assigned to -COO-, $-\mathrm{CH}_{2}$, and $-\mathrm{CH}_{3} \cdot{ }^{27,28}$ The high-resolution $\mathrm{O}$ 1s spectrum (Fig. 3d) can be fitted by two peaks, respectively centered at $533.3 \mathrm{eV}$ and $531.7 \mathrm{eV}$. These weak peaks can be assigned to $-\mathrm{COO}^{29}$ and $\mathrm{O}^{2-}$ ions within a $\mathrm{ZnO}$ matrix ${ }^{20,30}$ which indicated that $\mathrm{ZnO}$ microstructures are constructed and stearic acid is successfully modified on the stainless steel mesh surface. This is further confirmed by FT-IR (Fig. 4).
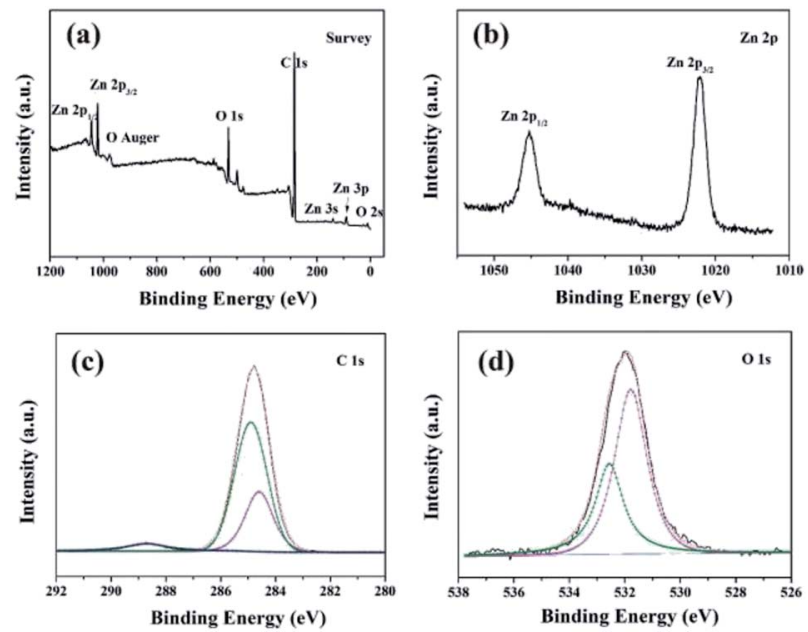

Fig. 3 XPS results for the superhydrophobic stainless steel mesh surface: (a) survey spectrum, (b) Zn 2p high-resolution spectrum, (c) C $1 \mathrm{~s}$ high-resolution spectrum, and (d) $\bigcirc 1$ s high-resolution spectrum.

Fig. 4 shows the FITR spectra of modified stainless-steel mesh surface and FTIR spectrum of pristine stainless steel mesh and $\mathrm{ZnO}$ coated stainless steel mesh are also given for comparison. In the case of pristine stainless steel mesh, the characteristic absorption bands in the range of $3570-3900 \mathrm{~cm}^{-1}$ and $1900-2400 \mathrm{~cm}^{-1}$ are assigned to the stretching vibrations of $\mathrm{O}-\mathrm{H}$ and $\mathrm{CO}_{2}$. The $\mathrm{ZnO}$ coated stainless steel mesh shows weak absorption bands at 2920, 2581 and $1534 \mathrm{~cm}^{-1}$ assign to the stretching vibration of the symmetric $-\mathrm{CH}_{2}$ stretch, the asymmetric $-\mathrm{CH}_{2}$ stretch and bending vibration of the antisymmetric carboxylate ion (-COO-). ${ }^{31,32}$ These weak peaks can be assigned to adsorbed zinc acetate. Compared with the $\mathrm{ZnO}$ coated mesh, the peaks at 1460 and $1397 \mathrm{~cm}^{-1}$ are observed for the superhydrophobic mesh. The strong characteristic peak at $1460 \mathrm{~cm}^{-1}$ is corresponding to the chelating coordination of zinc with stearic acid to form $\mathrm{CH}_{3}\left(\mathrm{CH}_{2}\right)_{16} \mathrm{COO}-\mathrm{Zn}$, ${ }^{33}$ indicating that the stearic acid modification results in a bond formation with $\mathrm{ZnO}$. The peak at $1390 \mathrm{~cm}^{-1}$ are assigned to the bending vibration of $-\mathrm{CH}_{3}{ }^{34}{ }^{34}$ What's more, the transmittance of the peaks at 2920

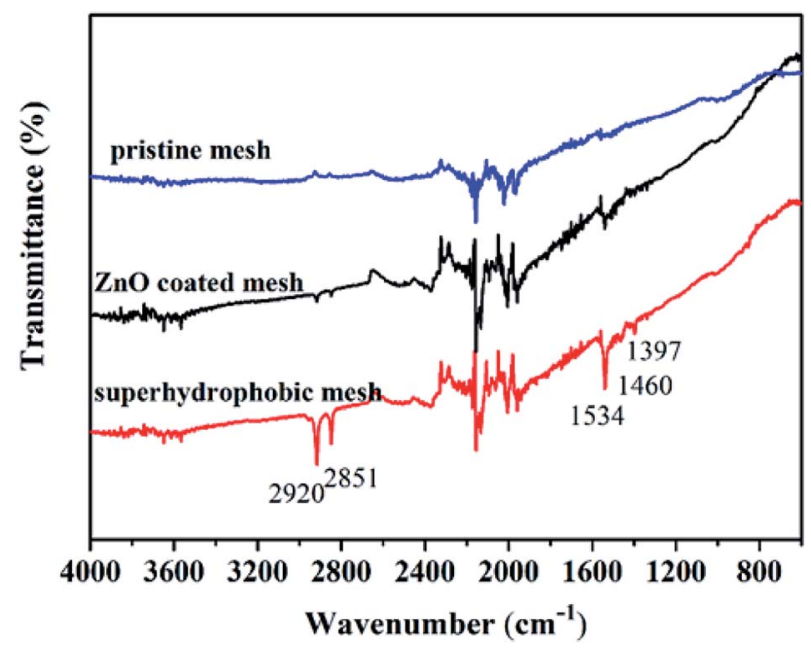

Fig. 4 FTIR spectra of stainless steel meshes. 
and $2850,1534 \mathrm{~cm}^{-1}$ of the superhydrophobic mesh obviously enhanced, which can be attributed to modified stearic acid. A combination of SEM, XPS and FTIR results show that the microand nano-scale hierarchical structures are constructed and low surface energy materials are successfully modified on the stainless steel mesh surface through this facile approach.

\section{Surface wettability analysis}

The surface wettability of the stainless steel meshes was evaluated by measuring the water and oil contact angle, and corresponding results are shown in Fig. 5. As shown in Fig. 5a and d, the pristine stainless steel mesh shows the amphiphilic nature with water and oil contact angle is $69^{\circ}$ and $0^{\circ}$. After the $\mathrm{ZnO}$ microstructures construction process, the $\mathrm{ZnO}$ coated stainless steel mesh exhibits special wettability. The water droplet keeps a highly spherical shape on the ZnO coated mesh while the oil droplet quickly spreading, the corresponding water contact angle is $122^{\circ}$ and oil contact angle is about $0^{\circ}$ (Fig. $5 \mathrm{~b}$ and e). The high hydrophobicity can be attributed to absorbed hydrophobic functional groups and $\mathrm{ZnO}$ microstructures. Fig. 5c and f show water droplets and oil droplets on $\mathrm{ZnO}$ coated stainless steel mesh followed by stearic acid modification, the water contact angle of $156^{\circ}$ and oil contact angle of about $0^{\circ}$ illustrates the prepared stainless steel meshes endowed superhydrophobic and superoleophilic properties simultaneously. Owing to connected the rough hierarchical structures and intrinsic hydrophobicity of stearic acid, the prepared mesh shows special wettability. As a proof of the special wettability, the photograph of a water droplet (Methylene blue colored) and an oil droplet
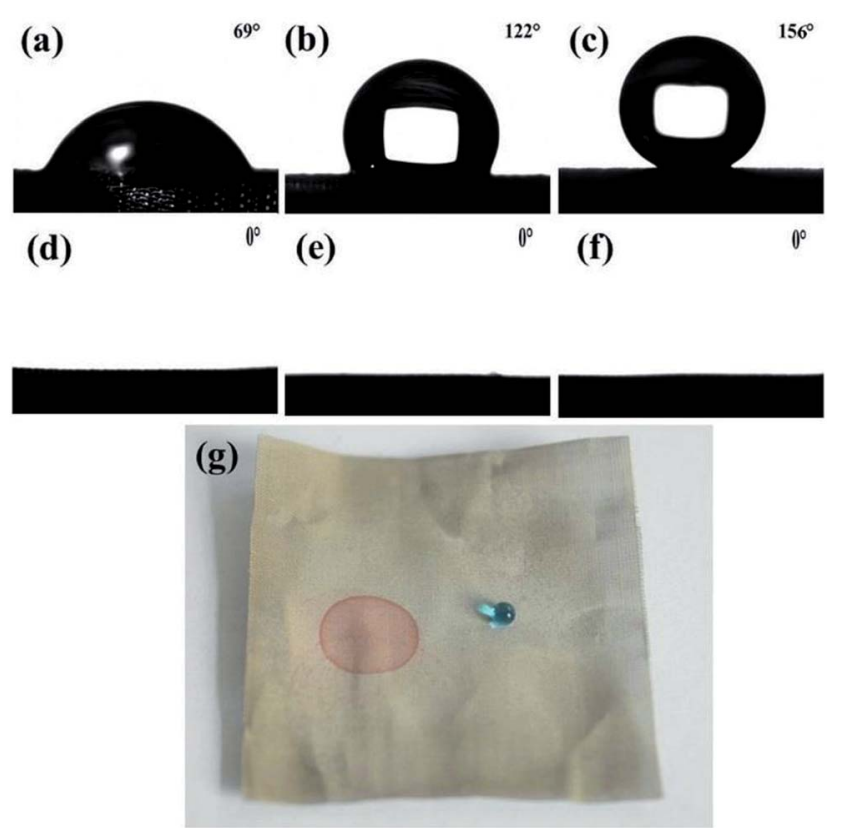

Fig. 5 Digital photographs of water droplet $(3 \mu \mathrm{L})$ shapes on stainless steel meshes surfaces: (a) pristine mesh, (b) ZnO coated mesh and (c) superhydrophobic mesh; digital photographs of $n$-hexane droplet ( 3 $\mu \mathrm{L})$ shapes on stainless steel meshes surfaces: (d) pristine mesh, (e) $\mathrm{ZnO}$ coated mesh and (f) superhydrophobic mesh; (g) photograph of Methylene blue colored water droplet and Sudan III colored oil droplet on the modified stainless steel mesh surfaces.
(Sudan III colored) on the superhydrophobic and superoleophilic stainless steel mesh surfaces is shown in Fig. 5g. It is observed that the red oil droplet spreads and water droplet keeps a sphere, so the surface shows good water repellent and oleophilic property.

\section{Mechanical durability, chemical stability and corrosion resistant property}

The durability and stability such as mechanical durability, chemical stability under acid and alkali conditions and corrosion resistance property are important indexes to evaluate the value of superhydrophobic and superoleophilic mesh for practical applications. The mechanical durability of the superhydrophobic mesh was examined by mechanical bending and twisting test and scratch test. The morphology of superhydrophobic mesh after mechanical bending and twisting is investigated and showed in Fig. 6a. The original morphology can be well maintained and no obvious micro and nanostructures fall off. What's more, the evolution of the water contact angle $v s$. friction times is shown in Fig. 6b. The water contact angle decreases from $156^{\circ}$ to $140^{\circ}$ within 8 frictions, and no significant change of water contact angle changes are observed with increasing friction time after 10 frictions. Chemical stability of the superhydrophobic mesh was evaluated by characterizing the contact angles of droplets with different pH values (Fig. 6c). The mesh can well maintain its superhydrophobic property, and water contact angles are all higher than $150^{\circ}$ under the different $\mathrm{pH}$ from 1 to 14 . Thus, as-prepared mesh has relatively good durability and stability.

The corrosion resistance of the superhydrophobic mesh was investigated in $3.5 \mathrm{wt} \% \mathrm{NaCl}$ solution and comparing those of the pristine mesh. Fig. $6 \mathrm{~d}$ shows the potentiodynamic
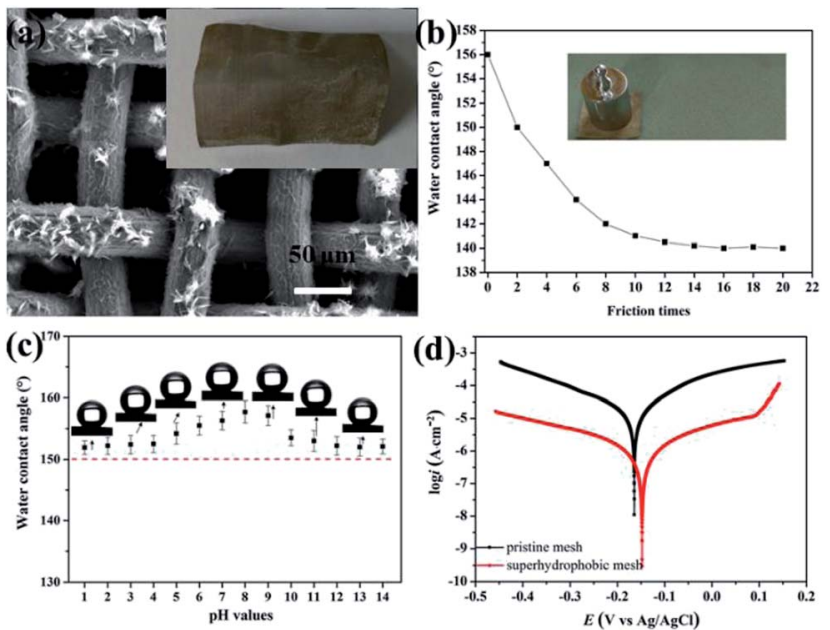

Fig. 6 The mechanical durability, chemical stability and anti-corrosion property of superhydrophobic stainless steel mesh. (a) SEM images of meshes after mechanical bending and twisting (inset: a digital photograph of the bended mesh), (b) influences of friction times on water contact angles, (c) the contact angles of droplets with different $\mathrm{pH}$ values $(\mathrm{pH}=1-14)$ and (d) potentiodynamic polarization curves of pristine and superhydrophobic mesh. 
polarization curves of pristine and superhydrophobic meshes. The corrosion potential $E_{\text {corr }}$ of the superhydrophobic mesh $(-0.148 \mathrm{~V})$ shifts about $20 \mathrm{mV}$ in the positive direction as compared to that of pristine mesh $(-0.165 \mathrm{~V})$. The corrosion current density $i_{\text {corr }}$ of the superhydrophobic mesh decreases to one-twelfth of that for pristine mesh from $2.032 \times 10^{-5} \mathrm{~A}$ to $1.698 \times 10^{-6} \mathrm{~A}$. As well known, a higher corrosion potential and a lower corrosion current density correspond to better corrosion resistance and a lower corrosion rate..$^{35}$ Obviously, the superhydrophobic mesh possesses better corrosion resistance. The corrosion resistance of the superhydrophobic mesh can be attributed to the following reason: $:^{27,35-37}$ the trapped air by the hierarchical structure acts as a physical barrier and such an air barrier not only can prevent corrosive ions from penetrating but also inhibit the electron transfer between the corrosive medium and the stainless steel mesh.

\section{Oil/water separation and floating oil collection performance}

In view of the above-demonstrated superwettability, the superhydrophobic and superoleophilic stainless steel mesh is predicted to be useful for oil-water mixture separation. As a proof of concept, oil/water mixture separation experiment of the as-prepared the superhydrophobic and superoleophilic mesh is performed and the separation procedure is shown in Fig. $7 \mathrm{a}$ and $\mathrm{b}$ and Movie S1. $\dagger$ The as-prepared mesh is fixed between two fixtures mounted glass tubes. A colored hexadecane-water mixture is poured along the glass tube. The hexadecane is selectively filtered while the water is hindered, which indicates that separation of oil/water mixtures is successfully achieved using the as-prepared mesh. In order to evaluate the performance of the as-prepared mesh in practical applications, a series of oil-water mixtures including 2,2,4-trimethyl pentane, petroleum ether, carbon tetrachloride and peanut oil were tested and corresponding separation efficiency is shown in Fig. $7 \mathrm{c}$. The as-prepared mesh exhibits the separation efficiency above $95.0 \%$ for all five oil-water mixtures. Furthermore, the asprepared mesh still retain the high separation efficiency above 95.1\% after 10 separation cycles for the hexane-water mixture (Fig. 7d), indicating good recyclability of the as-prepared mesh. Considering the industrial application and offshore oil spill, oil/ water separation meshes are often needed to be used in acidic or alkaline and sea water environments. Oil-water separation efficiency of the mesh in harsh environments was tested. The mesh exhibits high separation efficiencies above $95.0 \%$ for all the corrosive solutions and oil ( $n$-hexane) mixtures (Fig. 7e), revealing outstanding environmental stability. These results show that asprepared meshes has further potential applications in complex industrial oily wastewater treatment.

To expand the scope of application of the superhydrophobic and superoleophilic mesh, an oil skimmer device based on asprepared mesh is design for floating oil collection in situ. The collection and removal processes of floating oil using the asprepared oil skimmer are shown in Fig. 8a and Movie S2. $\dagger$ The part of mounted superhydrophobic and superoleophilic mesh always maintains contact with oil phase and water phase throughout the whole collection process. Once the oil skimmer is put into the oil-water mixture surface, the mesh is wetted

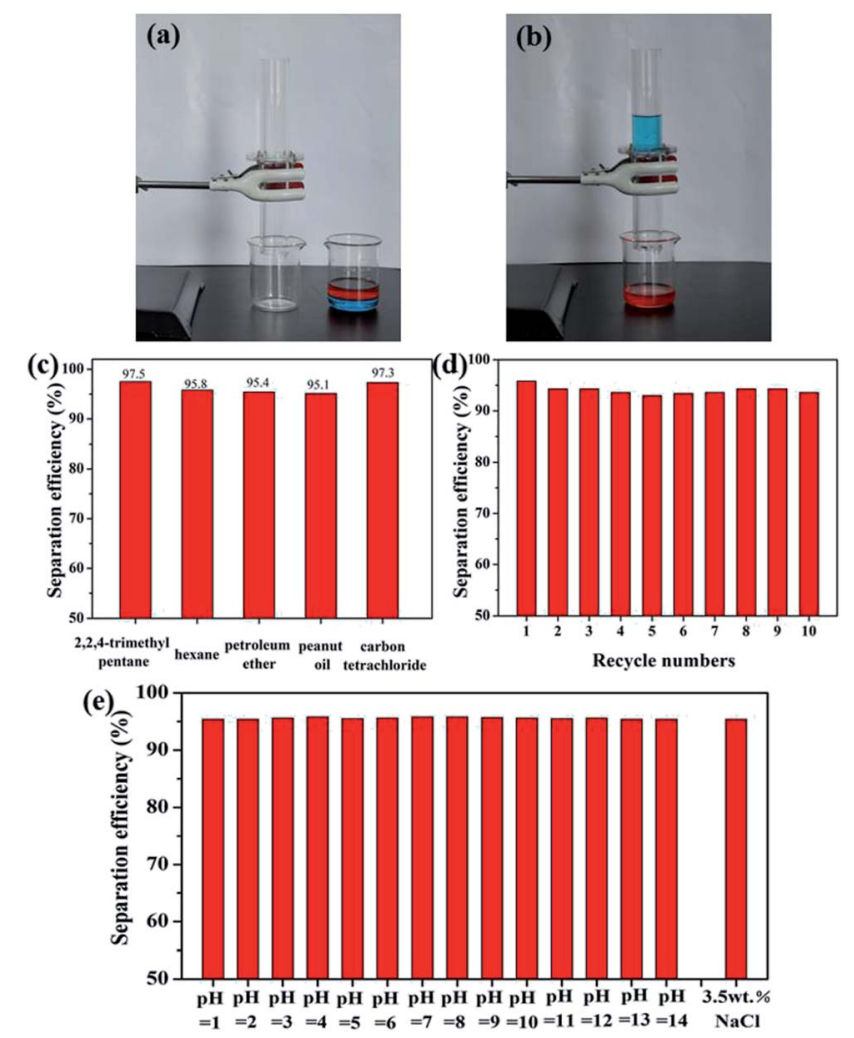

Fig. 7 Oil/water separation of superhydrophobic and superoleophilic stainless steel mesh (water is dyed with methylene blue and oil is dyed with Sudan III to enhance the visual effect): (a) before separation; (b) after separation; (c) the separation efficiency of the oil/water mixtures; (d) the oil/water separation efficiency versus the recycle numbers by taking the hexane-water mixture as an example and (e) the separation efficiency of the mesh for separating $n$-hexane and various corrosive solution mixtures.

immediately by floating oil and floating oil pass through the mesh fast and flow into the bottom of the oil skimmer. The oil skimmer with opposite wetting property to oils and water mesh endows an automatic collection and removal process of the floating oil. When the amount of the floating oil was less than the maximum capacity of the oil skimmer, the floating oil collection efficiency is always above $96 \%$ and even reaches to $96.9 \%$ for petroleum ether (Fig. 8b). Compared with as-prepared oil skimmer, the separation efficiency and collection method of reported superhydrophobic materials for floating oil collection are listed in Table 1. What's more, the oil skimmer exhibits high floating oil collection efficiency always remaining at above $95.2 \%$ after 5 times collection for the hexane-water mixture (Fig. 8c), which indicated the good recyclability of the as-prepared mesh.

\section{Oil-water separation mechanism}

According to the SEM, XPS and FT-IR analysis, the combined effect of the hierarchical structures and low surface energy endow the stainless steel mesh superhydrophobic and superoleophilic properties. To further explore the oil-water mixture separation mechanism of the superhydrophobic and superoleophilic stainless steel mesh, the super-wettability models are established and shown in Fig. 9. For these models, the pores of 

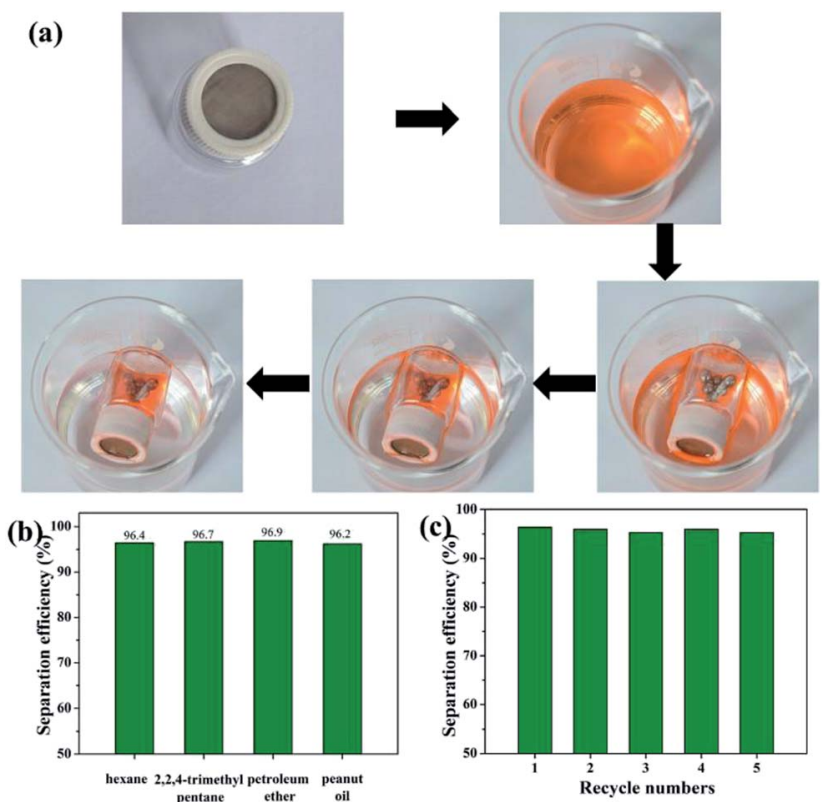

Fig. 8 Removal and collection processes of the floating oil using the oil skimmer: (a) removal and collection processes of hexane. (b) The separation efficiency of the oil skimmer for different oils, (c) the oil/ water separation efficiency versus the recycle numbers by taking the hexane as an example.

stainless steel mesh are assumed to be arranged in a regular square array. According to Laplace equation, ${ }^{42}$ superhydrophobic mesh (Fig. 9a) suffers from the positive intrusion pressure $\left(\Delta P_{\text {capillarity }}>0\right)$ due to negative capillary effect, which result in the water was repelled. In contrast, oil can permeate the mesh due to the negative intrusion pressure $\left(\Delta P_{\text {capillarity }}<0\right)$ from capillarity of the micropore. Furthermore, oil is trapped in the rough structures during the separation process, which resulted in increase of the repulsive force between water and

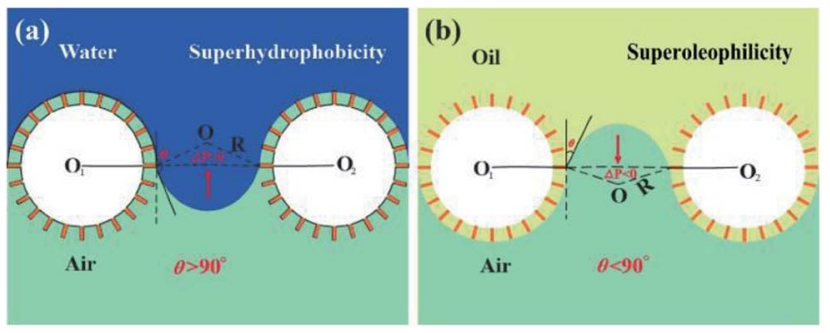

Fig. 9 Schematic illustration of liquid-wetting modes of the superhydrophobic and superoleophilic mesh: (a) water wetting model of the coated mesh. (b) Oil wetting model of the coated mesh. $O$ is the center of the spherical cap of the meniscus; $\mathrm{O}_{1}$ and $\mathrm{O}_{2}$ are the cross-section center of the mesh.

mesh. ${ }^{43}$ Therefore, the superhydrophobic and superoleophilic properties facilitate the separation of oil-water mixtures efficiently. Similarly, the mesh mounted on oil skimmer is also subjected to similar intrusion pressure. Therefore, the oil skimmer is able to realize floating oil collection.

\section{Conclusions}

In conclusion, ZnO coated superhydrophobic and superoleophilic stainless steel meshes is prepared through a facile and inexpensive chemical immersion growth and subsequent surface modification with WCA of $156^{\circ}$ and OCA of $0^{\circ}$. Furthermore, as-prepared mesh could be employed to separate various oil-water mixtures driven by gravity with an oil-water separation efficiency larger than $95 \%$. Meanwhile, a new oil skimmer based on the as-prepared mesh is proposed to spontaneous collect floating oil with oil collection efficiency above $96 \%$. Importantly, the oil-water separation efficiency and floating oil collection can retain their high efficiency even after 5 cycles. This facile and novel oil skimmer based as-prepared stainless steel mesh combined with good mechanical

Table 1 Comparison of various superhydrophobic materials for floating oil collection

\begin{tabular}{|c|c|c|c|c|c|}
\hline Substrate materials & WCA $\left(^{\circ}\right)$ & Oils & Separation efficient (\%) & Collection method & Ref. \\
\hline \multirow[t]{4}{*}{ Copper mesh } & \multirow[t]{4}{*}{157} & Hexadecane & 97.5 & \multirow[t]{4}{*}{ Manual } & \multirow[t]{4}{*}{38} \\
\hline & & Gasoline & 96.3 & & \\
\hline & & Toluene & 96.9 & & \\
\hline & & Mineral oil & 95.7 & & \\
\hline \multirow[t]{6}{*}{ Fabrics } & \multirow[t]{6}{*}{158} & Hexadecane & 99.98 & \multirow[t]{6}{*}{ Manual } & \multirow[t]{6}{*}{39} \\
\hline & & Cyclohexane & 99.96 & & \\
\hline & & Petroleum ether & 99.98 & & \\
\hline & & Vegetable oil & 99.98 & & \\
\hline & & Soybean oil & 99.97 & & \\
\hline & & Vacuum pump oil & 99.95 & & \\
\hline 40 mesh stainless steel & 144 & Oil & - & Automatic & 40 \\
\hline \multirow[t]{4}{*}{$\mathrm{Cu}$ foam } & \multirow[t]{4}{*}{151} & Hexane & 98.5 & \multirow[t]{4}{*}{ Automatic } & \multirow[t]{4}{*}{41} \\
\hline & & Hexadecane & 97.6 & & \\
\hline & & Mineral oil & 94.3 & & \\
\hline & & Corn oil & 91.9 & & \\
\hline \multirow[t]{4}{*}{ Stainless steel mesh } & \multirow[t]{4}{*}{156} & Hexane & 96.4 & \multirow[t]{4}{*}{ Automatic } & \multirow[t]{4}{*}{ This work } \\
\hline & & 2,2,4-Trimethyl pentane & 96.7 & & \\
\hline & & Petroleum ether & 96.9 & & \\
\hline & & Peanut oil & 96.2 & & \\
\hline
\end{tabular}


durability, chemical stability and corrosion-resistant properties, which makes it an ideal candidate for application in floating oil collection on the ocean and stable oily wastewater.

\section{Conflicts of interest}

There are no conflicts to declare.

\section{Acknowledgements}

The authors gratefully acknowledge the Natural Science Foundation of Shanxi Province (grant no. 201701D121041), the Science and Technology Innovation Project of Shanxi Higher Education (grant no. 2017159), the Shanxi Key Subjects Constructions (SKSC), the Collaborative Innovation Center of Shanxi Key Basic Materials, the Central Special Funds Guiding the Development of Local Science and Technology (grant no. YDZX20181400002967), and the PhD Scientific Research Startup Foundation (grant no. 20162014) of TYUST for funding provided in support of this work.

\section{Notes and references}

1 M. M. Pendergast and E. M. V. Hoek, Energy Environ. Sci., 2011, 4, 1946.

2 R. P. Schwarzenbach, T. Egli, T. B. Hofstetter, U. von Gunten and B. Wehrli, Annu. Rev. Environ. Resour., 2010, 35, 109136.

3 M. A. Shannon, P. W. Bohn, M. Elimelech, J. G. Georgiadis, B. J. Marinas and A. M. Mayes, Nature, 2008, 452, 301310.

4 Y. Yang, H. Wang, J. X. Li, B. Q. He, T. H. Wang and S. J. Liao, Environ. Sci. Technol., 2012, 46, 6815.

5 Y. Dou, D. Tian, Z. Sun, Q. Liu, N. Zhang, J. H. Kim, L. Jiang and S. X. Dou, ACS Nano, 2017, 11, 2477.

6 S. Y. Zhang, F. Lu, L. Tao, N. Liu, C. R. Gao, L. Feng and Y. Wei, ACS Appl. Mater. Interfaces, 2013, 5, 11971.

7 Z. Xu, D. Y. Jiang, Z. B. Wei, J. Chen and J. F. Jing, Appl. Surf. Sci., 2018, 427, 253.

8 S. K. Hubadillah, P. Kumar, M. H. D. Othman, A. F. Ismail, M. A. Rahman and J. Jaafar, RSC Adv., 2018, 8, 2986-2995.

9 G. N. Ren, Y. M. Song, X. M. Li, Y. L. Zhou, Z. Z. Zhang and X. T. Zhu, Appl. Surf. Sci., 2018, 428, 520.

10 Z. Shi, W. Zhang, F. Zhang, X. Liu, D. Wang, J. Jin and L. Jiang, Adv. Mater., 2013, 25, 2422.

11 X. Gao, L. P. Xu, Z. Xue, L. Feng, J. Peng, Y. Wen, S. Wang and X. Zhang, Adv. Mater., 2014, 26, 1771.

12 Z. Xue, S. Wang, L. Lin, L. Chen, M. Liu, L. Feng and L. Jiang, Adv. Mater., 2011, 23, 4270.

13 K. Kota, G. Kwon, W. Choi, J. M. Mabry and A. Tuteja, Nat. Commun., 2012, 3, 1025.

14 H. Yoon, S. H. Na, J. Y. Choi, S. S. Latthe, M. T. Swihart, S. S. Al-Deyab and S. S. Yoon, Langmuir, 2014, 30, 11761.

15 F. Zhang, W. Zhang, Z. Shi, D. Wang, J. Jin and L. Jiang, Adv. Mater., 2013, 25, 4192.

16 H. J. Cao, J. Y. Fu, Y. Liu and S. G. Chen, Colloids Surf., A, 2018, 537, 294.

17 Z. Xu, D. Y. Jiang, Z. B. Wei, J. Chen and J. F. Jing, Appl. Surf. Sci., 2018, 427, 253.
18 R. Gao, Q. Liu, J. Wang, J. Y. Liu, W. L. Yang, Z. Gao and L. H. Liu, Appl. Surf. Sci., 2014, 289, 417.

19 J. Yong, F. Chen, Q. Yang, Y. Fang, J. L. Huo and X. Hou, Chem. Commun., 2015, 51, 9813.

20 Y. Huang, D. K. Sarkar and X. G. Chen, Appl. Surf. Sci., 2015, $327,327$.

21 E. Velayi and R. Norouzbeigi, Appl. Surf. Sci., 2018, 441, 156.

22 H. Lu, X. Y. Zhai, W. W. Liu, M. Zhang and M. Guo, Thin Solid Films, 2015, 586, 46.

23 X. F. Wang, H. Lu, W. W. Liu, M. Guo and M. Zhang, Ceram. Int., 2017, 43, 6460.

24 D. Nesheva, V. Dzhurkov, I. Stambolova, V. Blaskov, I. Bineva, J. M. C. Moreno, S. Preda, M. Gartner, T. H. Vasileva and M. Shipochka, Mater. Chem. Phys., 2018, 209, 165.

25 D. G. Ayana, R. Ceccato, C. Collini, L. Lorenzelli, V. Prusakova and S. Dirè, Mater. Res. Bull., 2013, 48, 25.

26 H. Li, M. J. Zheng, S. D. Liu, Li. Ma, C. Q. Zhu and Z. Z. Xiong, Surf. Coat. Technol., 2013, 224, 88.

27 L. J. Li, Z. Y. Zhang, J. L. Lei, J. X. He, R. Lv, N. N. Li and F. S. Pan, Corros. Sci., 2014, 85, 174.

28 N. E. Zaffiropoulos, P. E. Vickers and C. A. Baillie, J. Mater. Sci., 2003, 38, 3903.

29 G. L. Fisher, A. V. Walker, A. E. Hooper, T. B. Tighe, K. B. Bahnck, H. T. Skriba, M. D. Reinard, B. C. Haynie, R. L. Opila, N. Winograd and D. L. Allara, J. Am. Chem. Soc., 2002, 124, 5528.

30 K. G. Saw, K. Ibrahim, Y. T. Lim and M. K. Chai, Thin Solid Films, 2007, 515, 2879.

31 L. Li, H. Q. Yang, J. Yu, Y. Chen, J. H. Ma, J. Y. Zhang, Y. Z. Song and F. Gao, J. Cryst. Growth, 2009, 311, 4199.

32 K. Yang, H. B. Peng, Y. H. Wen and N. Li, Appl. Surf. Sci., 2010, 256, 3093.

33 H. Li, M. Zheng, L. Ma, C. Zhu and S. Lu, Mater. Res. Bull., 2013, 48, 25.

34 Y. Feng, S. Chen and Y. Frank Cheng, Surf. Coat. Technol., 2018, 340, 55.

35 P. Wang, D. Zhang, R. Qiu and B. Hou, Corros. Sci., 2001, 53, 2080.

36 E. Velayi and R. Norouzbeigi, Appl. Surf. Sci., 2017, 426, 674. 37 Y. Shi, Y. Wu, X. Feng, Y. Wang, G. Yue and S. Jin, Appl. Surf. Sci., 2016, 367, 493.

38 G. Ren, Y. Song, X. Li, Y. Zhou, Z. Zhang and X. Zhu, Appl. Surf. Sci., 2018, 428, 520.

39 C. L. Zhang, P. Li and B. Cao, Ind. Eng. Chem. Res., 2018, 57, 329.

40 Y. Xu, M. Liu, H. Li and A. Wali, Surf. Coat. Technol., 2017, 325, 661.

41 J. L. Song, Y. Lu, J. Luo, S. Huang, L. Wang, W. L. Xu and I. P. Parkin, Adv. Mater. Interfaces, 2015, 2, 1500350.

42 R. Zhou, S. D. Lin, F. Shen, S. Y. Khew and M. H. Hong, Surf. Coat. Technol., 2018, 348, 73.

43 E. S. Zhang, Z. J. Cheng, T. Lv, Y. H. Qian and Y. Y. Liu, J. Mater. Chem. A, 2015, 3, 13411. 